\title{
Gas exchange, biomass and non-structural carbohydrates dynamics in vines under combined drought and biotic stress
}

\author{
Tadeja Savi ${ }^{12^{*}}$ D, Almudena García González², Jose Carlos Herrera² and Astrid Forneck²
}

\begin{abstract}
Background: Intensity of drought stress and pest attacks is forecasted to increase in the near future posing a serious threat to natural and agricultural ecosystems. Knowledge on potential effects of a combined abiotic-biotic stress on whole-plant physiology is lacking. We monitored the water status and carbon metabolism of a vine rootstock with or without scion subjected to water shortening and/or infestation with the sucking insect phylloxera (Daktulosphaira vitifoliae Fitch). We measured non-structural carbohydrates and biomass of different plant organs to assess the stress-induced responses at the root, stem, and leaf level. Effects of watering on root infestation were also addressed.

Results: Higher root infestation was observed in drought-stressed plants compared to well-watered. The drought had a significant impact on most of the measured functional traits. Phylloxera further influenced vines water and carbon metabolism and enforced the sink strength of the roots by stimulating photosynthates translocation. The insect induced carbon depletion, reprogramed vine development, while preventing biomass compensation. A synergic effect of biotic-abiotic stress could be detected in several physiological and morphological traits.

Conclusions: Our results indicate that events of water shortage favour insects' feeding damage and increase the abundance of root nodosities. Root phylloxera infestation imposes a considerable stress to the plants which might exacerbate the negative effects of drought.
\end{abstract}

Keywords: Abiotic stress, Water status, Herbivory, Phylloxera, Vitis vinifera, Riesling

\section{Background}

Climate change has increased the number of abiotic and biotic stressors in several ecosystems worldwide, impacting plant growth and production (Suzuki et al., 2014 [6]; ). Among abiotic stressors, variations in temperatures and rainfalls represent the biggest risk factor for survival of vegetation in both natural and agricultural ecosystems ([45]; Suzuki et al., 2014). Intense or prolonged drought usually leads to photosynthesis limitation, decreases the xylem water potential, and induces embolism formation with consequent reduction of water transport efficiency

\footnotetext{
* Correspondence: tadeja.savi@boku.ac.at

'Department of Integrative Biology and Biodiversity Research, University of Natural Resources and Life Sciences, Vienna (BOKU), Institute of Botany, Gregor-Mendel-Straße 33, 1190 Vienna, Austria

${ }^{2}$ Department of Crop Sciences, University of Natural Resources and Life Sciences, Vienna (BOKU), Institute of Viticulture and Pomology, Konrad Lorenz Strasse 24, A-3430 Tulln, Austria
}

$[22,29,43]$. A large body of research on grapevines has improved our understanding of the physiological responses of different genotypes under drought $[8,25,28]$. However, beside the drought stress, insect pests and plant pathogens, in particular fungi and viruses represent a serious concern worldwide, since they exert an impact on vine physiology and health $[6,16,33,37]$. The range of insect pests and pathogens can be influenced by climate change and their incidence is expected to further increase in the upcoming decades ([12, 38]; Suzuki et al., 2014 [6];) with consequent significant impacts on the winemaking sector (Suzuki et al., 2014 [16];).

Grape phylloxera (Daktulosphaira vitifoliae Fitch) is one of the most economically destructive and geographically widespread pests of commercial grapevines. It is a sucking and sedentary insect, obligate biotroph of Vitis species, native to North America where it coexists with native vine species $[17,24]$. It was accidentally globally

(c) The Author(s). 2019 Open Access This article is distributed under the terms of the Creative Commons Attribution 4.0 International License (http://creativecommons.org/licenses/by/4.0/), which permits unrestricted use, distribution, and 
spread in the nineteenth century causing irreversible economic losses to the viticultural industry. Phylloxeratolerant rootstocks with parentage of American Vitis species have been developed and successfully employed in the last century to buffer the detrimental effects of the pest $[4,37]$. However, starting from the 80 's of the twentieth century, new outbreaks of phylloxera have been reported in Europe, Australia, South and North America endangering once again the viticulture [5, 37]. Moreover, rootstocks breakdown or failure due to the presence of more aggressive phylloxera biotypes has been also reported $[15,37]$.

Phylloxera feeds on parenchymal cells content and does not appear to penetrate vascular tissue [14, 24]. Different biotypes of the insect can attack root and/or leaf organs, but root-feeding stages are the most economically damaging $[4,15,30,37]$. Feeding induces the formation of nodosities and tuberosities on young and mature roots, respectively ([17]; Battey and Simmonds, 2005). Root infestation apparently alters the water and nutrient absorbance capacity of plants [36], the pest competes for photosynthates leading to the enhancement of the carbon sink activity of roots $[10,14,18,23$, 24]. Furthermore, wounding may produce entry points for soilborne pathogens which stimulate infections and secondary necrosis [23, 32] causing increased mortality of younger roots [3]. As a result of root damage, symptoms of intense phylloxera infestation are generally visible as reduced canopy vigour, premature leaf yellowing and smaller bunch size $[4,32]$. Knowledge on how the different cultivars of vines respond to the root phylloxera attack, how the invasive insect influences whole-plant physiological functions, growth, and development is limited. Moreover, information on potential effects of a combined drought-root phylloxera stress on grapevine is particularly lacking in the scientific literature $[2,5]$. In the light of prolonged drought periods coupled to high pests' pressure, understanding and predicting the potential effects of a combined biotic-abiotic stress on vine represent a challenge for the future of viticulture.

To fill this knowledge gap, the present research project is aimed at investigating the physiology and carbon allocation of Riesling grafted on Teleki 5C, an economically important rootstock, under future "natural" growing conditions, characterized by prolonged drought periods and abundance of pests $[6,45]$. Firstly, we wanted to shed light into the effects of watering on root phylloxeration. Secondly, we aimed to monitor the water status and whole-plant carbon metabolism of the vines subjected to water limitation or phylloxera infestation in order to improve our knowledge on the stress-induced plant responses at the root, stem, and leaf level. Furthermore, we wanted to assess, for the first time, eventual cumulative/synergic effects of the coupled biotic-abiotic stress on vine physiology, and highlight eventual compensation strategies of the host that might mitigate the damage and eventual negative effects of the pest on metabolism and development.

\section{Results}

Effects of the watering regime on root phylloxeration

After the acclimation period, the experimental vines were exposed to an eight-week long drought and/or phylloxera treatment. During this time interval the greenhouse temperatures averaged about $27^{\circ} \mathrm{C}$ with minimum and maximum peaks of $10^{\circ} \mathrm{C}$ and $46^{\circ} \mathrm{C}$, respectively. The average midday water pressure deficit oscillated between 0.6 and $5.5 \mathrm{kPa}$ (Additional file 1: Figure S1). During the hottest hours of the day, the substrate temperatures were lower compared to those of the air by about $5^{\circ} \mathrm{C}$ and $8{ }^{\circ} \mathrm{C}$ in $\mathrm{D}$ and $\mathrm{W}$ pots, respectively.

The root infestation, analyzed at the end of the experiment, did not differ significantly between $5 \mathrm{C}$ and RR plants (same rootstock used); hence data were averaged and reported in Fig. 1. In well-watered vines (soil water content = $\left.0.3 \pm 0.04 \mathrm{gg}^{-1}, \mathrm{~W}\right)$ the infestation frequency was 0.64 , while in drought-stressed plants (soil water content $=0.1 \pm$ $\left.0.01 \mathrm{gg}^{-1}, \mathrm{D}\right)$ it increased up to 0.97 . Compared to W vines, a significantly higher number of $\mathrm{D}$ plants showed intense infestation symptoms and fell in the assessment class "4" (> 200 nodosities, presence of tuberosities).

\section{Gas-exchange, water status and photosynthetic efficiency} of the study vines

Figures 2 and 3 report the transpiration rate $\left(\mathrm{E}_{\mathrm{L}}\right)$ and net photosynthesis (A) measured in $5 \mathrm{C}$ (Figs. 2a and 3a)

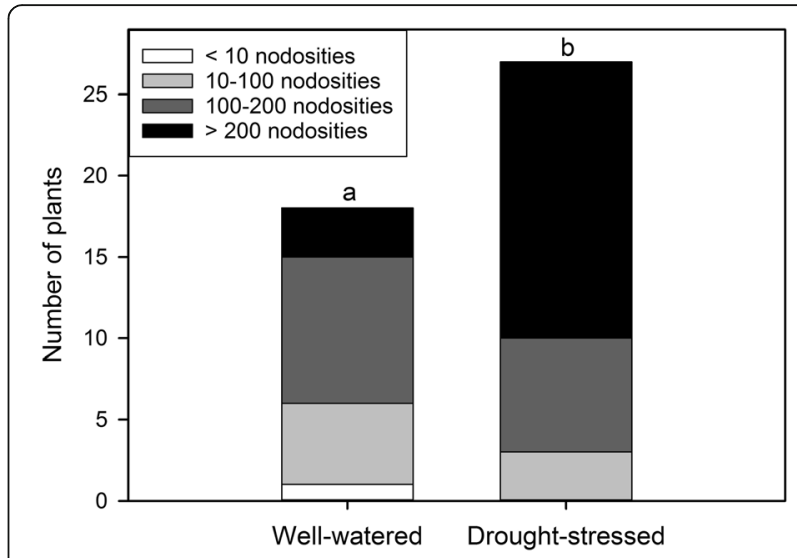

Fig. 1 Root infestation evaluated at the end of the eight-week long treatment in well-watered and drought-stressed 5C and Riesling grafted on $5 \mathrm{C}$ grapevines (pooled data). Infestation intensity is classified as follows: 1 = presence of a low number of root nodosities (white stripes); $2=10$ to 100 nodosities (light grey stripes); $3=$ up to 200 nodosities (dark grey stripes); 4 > 200 nodosities (black stripes), presence of tuberosities on older lignified roots. Lettering denotes a statistically significant difference between groups (chi-square test) 


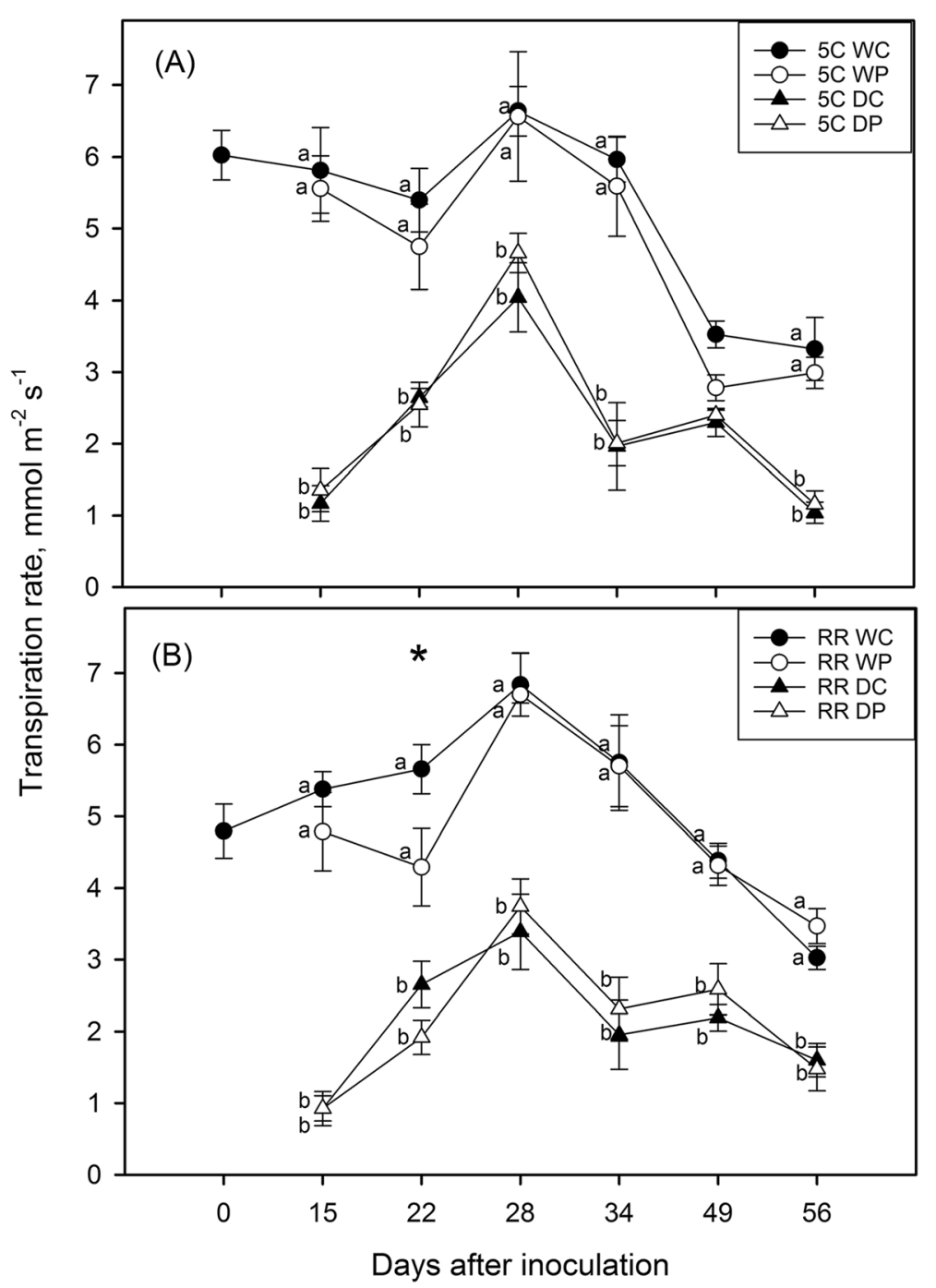

Fig. 2 Transpiration rate $\left(E_{L}\right)$ measured in $5 C(\mathbf{a})$ and Riesling grafted on $5 C(\mathbf{b})$ during treatments application $(n=4-7)$. W=well-watered plants; $D=$ drought-stressed; $C=$ control, non-phylloxerated; $P=$ root phylloxerated. Letters and asterisk indicate statistically significant difference within Irrigation (Factor I; W and D) and Infestation (Factor II; C and P), respectively. A significant interaction between factors (Irr x Inf) was observed in 5C on the 49th day after inoculation, i.e. within W level: C > P; within C level: W>D

and Riesling grafted on 5C (Figs. $2 \mathrm{~b}$ and $3 \mathrm{~b}$ ) plants on a weekly basis. The imposed moderate water deficit $\left(\psi_{\text {stem }}\right.$ and $\psi_{\min }$ of about -1.0 and $-1.20 \mathrm{MPa}$, respectively; Table 1) significantly reduced both $\mathrm{E}_{\mathrm{L}}$ and $\mathrm{A}$. The stomatal conductance $\left(\mathrm{g}_{\mathrm{s}}\right)$ and sub-stomatal $\mathrm{CO}_{2}$ (ci) followed a similar trend to $E_{L}$, while leaf temperature $\left(T_{\text {leaf }}\right)$ ranged between $32^{\circ} \mathrm{C}$ and $40^{\circ} \mathrm{C}$, with the highest peaks recorded mostly in drought-stressed plants (Additional file 1: Figures. S2-S4). As expected, all traits were significantly affected by drought in both studied genotypes, even if photosynthetic rates and leaf temperature on a smaller extend compared to stomatal conductance, sub-stomatal $\mathrm{CO}_{2}$ and transpiration. On the other hand, phylloxera infestation did not induce notable shifts in the physiological traits, with the exception of $\mathrm{E}_{\mathrm{L}}$ and $\mathrm{g}_{\mathrm{s}}$ measured in RR vines three weeks after inoculation (30\% lower values recorded in $\mathrm{P}$ than in $\mathrm{C}$ group), and $\psi_{\min }$ measured in $5 \mathrm{C}$ (Table 1$)$ on the last sampling day $(-1.20 \mathrm{vs}-1.05 \mathrm{MPa}$ measured in $\mathrm{P}$ and $\mathrm{C}$ group, respectively). Additionally, in $5 \mathrm{C}$ vines a significant interaction (Irrigation $\mathrm{x}$ Infestation) pointed out that in well-watered plants the $\mathrm{E}_{\mathrm{L}}$ was, once again, 20\% lower in P compared to C (Fig. 2a, 7 weeks after inoculation). The photosynthetic efficiency was apparently far less sensible to drought during the study period (data not shown), but a significant interaction between factors was highlighted in RR on the last sampling date (Table 1) with lower $\mathrm{Fv} / \mathrm{Fm}$ displayed by the leaves under the biotic attack.

\section{Morphological traits of the study vines}

Not surprisingly, the shoot length and aboveground biomass of both genotypes were higher in $\mathrm{W}$ plants than in 


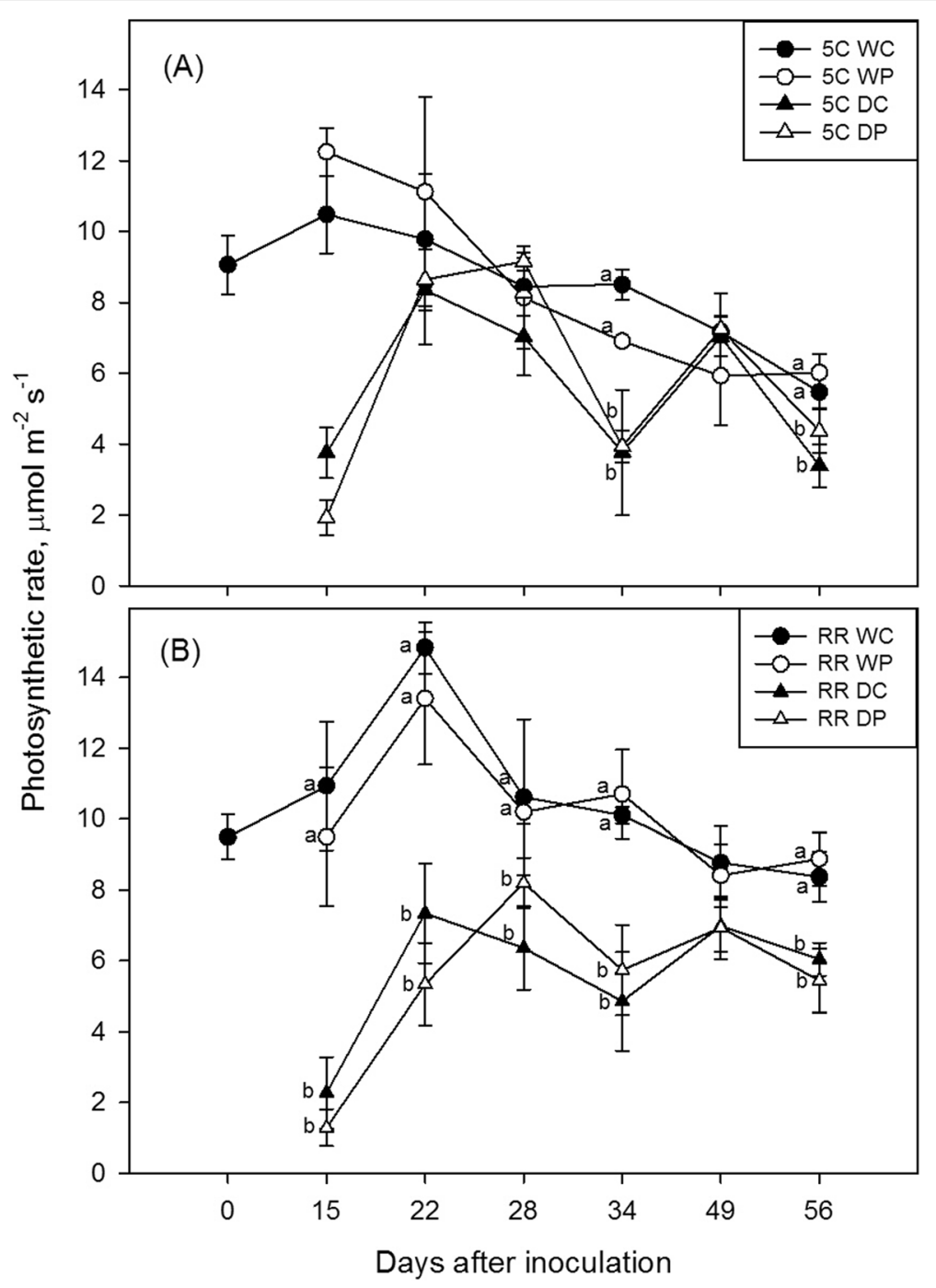

Fig. 3 Photosynthetic rate (A) measured in $5 C$ (a) and Riesling grafted on $5 C$ (b) during treatments application $(n=4-7)$. W=well-watered plants; $D=$ drought-stressed; $C=$ control, non-phylloxerated; $P=$ root phylloxerated. Letters denote statistically significant differences within Irrigation (Factor I; W and D), while n.s. indicates the lack of differences. A significant interaction between factors (Irr x Inf) was observed in 5C on 15th and 22nd day after stress imposition, i.e. within C level: W > D; within P level: W > D. No statistically significant differences within factor Infestation were observed

Table 1 Leaf temperature $\left(T_{\text {leaf }}\right)$, photosynthetic efficiency (Fv/Fm), stem and minimum water potential $\left(\psi_{\text {stem }}\right.$ and $\left.\psi_{\text {min }}\right)$ measured in $5 C$ and Riesling $\times 5 C(R R)$ plants 8 weeks after the beginning of treatments $(n=5-8)$. W = well-watered plants; $D=$ droughtstressed; $C=$ control, non-phylloxerated; $\mathrm{P}=$ root phylloxerated. * indicates statistically significant differences within the factors (Irrigation or Infestation). A significant interaction between factors (Irr x Inf) was observed in Fv/Fm measured in RR, i.e. within W level: C > P; within P level: $W<D$

\begin{tabular}{|c|c|c|c|c|c|c|c|c|c|c|}
\hline \multirow{3}{*}{ Traits } & \multicolumn{5}{|l|}{$5 C$} & \multicolumn{5}{|l|}{$\mathrm{RR}$} \\
\hline & \multicolumn{2}{|l|}{ Irrigation } & \multicolumn{2}{|l|}{ Infestation } & \multirow{2}{*}{$\begin{array}{l}\text { Interaction } \\
\operatorname{lrr} x \operatorname{lnf}\end{array}$} & \multicolumn{2}{|l|}{ Irrigation } & \multicolumn{2}{|l|}{ Infestation } & \multirow{2}{*}{$\begin{array}{l}\text { Interaction } \\
\operatorname{lr} \times \operatorname{lnf}\end{array}$} \\
\hline & W & $\mathrm{D}$ & C & $P$ & & W & $\mathrm{D}$ & $C$ & $P$ & \\
\hline Tleaf, ${ }^{\circ} \mathrm{C}$ & $32.6 \pm 0.5$ & $33.5 \pm 0.6$ & $32.8 \pm 0.5$ & $33.3 \pm 0.6$ & n.s. & $31.6 \pm 0.6$ & $33.5 \pm 0.7^{*}$ & $32.1 \pm 0.6$ & $33.0 \pm 0.7$ & n.s. \\
\hline $\mathrm{Fv} / \mathrm{Fm}$ & $0.80 \pm 0.01$ & $0.81 \pm 0.01$ & $0.80 \pm 0.01$ & $0.81 \pm 0.01$ & n.s. & $0.78 \pm 0.01$ & $0.79 \pm 0.01$ & $0.79 \pm 0.01$ & $0.77 \pm 0.01$ & $*$ \\
\hline$\psi_{\text {stem }},-\mathrm{MPa}$ & $0.64 \pm 0.03$ & $1.08 \pm 0.03^{*}$ & $0.85 \pm 0.03$ & $0.87 \pm 0.03$ & n.s. & $0.54 \pm 0.04$ & $0.89 \pm 0.04^{*}$ & $0.72 \pm 0.04$ & $0.71 \pm 0.04$ & n.s. \\
\hline$\psi_{\min ,}-\mathrm{MPa}$ & $1.00 \pm 0.04$ & $1.29 \pm 0.04^{*}$ & $1.08 \pm 0.04$ & $1.20 \pm 0.04^{*}$ & n.s. & $0.82 \pm 0.04$ & $1.10 \pm 0.05^{*}$ & $0.97 \pm 0.04$ & $0.95 \pm 0.05$ & n.s. \\
\hline
\end{tabular}


$\mathrm{D}$ ones (Table 2). The phylloxeration in RR plants subjected to drought induced a slight reduction of both shoot length and biomass, but a significant difference was highlighted only in the roots' dry biomass $(19.9 \pm 1.3$ vs $23.8 \pm 1.4 \mathrm{~g}$ for $\mathrm{P}$ and $\mathrm{C}$, respectively; interaction Irrigation $\mathrm{x}$ Infestation). Moreover, the biotic threat reduced significantly the leaf mass allocation in RR plants (LMA of $5.6 \pm 0.2 \mathrm{~g} \mathrm{~cm}^{-2}$ in $\mathrm{P}$ and $6.1 \pm 0.1 \mathrm{~g} \mathrm{~cm}^{-2}$ in $\mathrm{C}$ group), but not in $5 \mathrm{C}$.

\section{Non-structural carbohydrates (NSC) content}

NSC measured in leaves, stems, and roots are summarized in Table $3(\mathrm{a}-\mathrm{c})$. Overall, the concentration of soluble carbohydrates was relatively higher in roots, followed by leaves and stems, while starch was much more abundant in roots and stems than in leaves. All plants subjected to drought showed a lower glucose and fructose concentration in the leaves (by about $40 \%$ compared to well-watered), but the starch content was negatively affected only in RR. At the stem level, the water scarcity led to a decrease of glucose and fructose in $5 \mathrm{C}$ plants, while an opposite trend was observed in RR. Significant differences in sucrose (the major transport sugar form) were observed only at the root level, where it peaked up to $95 \mathrm{mgg}^{-1}$ in the D group and reached only $78 \mathrm{mgg}^{-1}$ in W. Once again, the drought led to a depletion of glucose and starch in the roots of RR plants, but not of $5 \mathrm{C}$.

Apparently, phylloxeration didn't induce marked shifts of NSC in the aboveground organs of both genotypes studied (Table $3 \mathrm{a}, \mathrm{b}$ ), with the exception of a sharp reduction of starch in RR leaves $(4.8 \pm 1.1$ and $8.2 \pm 1.0 \mathrm{mg} \mathrm{g}^{-1}$, measured in $\mathrm{P}$ and $\mathrm{C}$ plants respectively). On the other hand, roots responded to the biotic attack with a significant reduction (by about $50 \%$ ) of all soluble sugars (Table 3c). Furthermore, a significant interaction between irrigation and infestation was highlighted for the root glucose measured in $\mathrm{RR}$ and sucrose measured in $5 \mathrm{C}$.

\section{Discussion}

Under climate change, the spread and accelerated reproduction of phylloxera represent a potential threat for the wine industry. We monitored the whole-plant response to abiotic and/or biotic stress through measurements of vine water and carbon metabolism, carbohydrate partitioning, and below/aboveground biomass allocation. We found evidence that the combination of drought and herbivory stress significantly impact water status and carbon allocation of grapevines.

Teleki $5 \mathrm{C}$ turned out to be a tolerant rootstock able to support the proliferation of phylloxera on nodosities. Despite the high temperatures recorded during the study period with daily maximum above $45^{\circ} \mathrm{C}$ (Additional file 1: Fig. S1, substrate temperatures above $40^{\circ} \mathrm{C}$ ), the root inoculation was successful in $84 \%$ of plants, suggesting that previously reported optimal ambient temperatures for phylloxera survival and gall formation ranging between 22 and $30{ }^{\circ} \mathrm{C}[17,37]$ should be re-considered and/or potentially heat-resistant phylloxera biotypes have evolved. It has been suggested that, apart from the temperature, a range of other abiotic factors including type of the soil, seasonality and humidity $[7,17,37]$ influence the survival and reproduction of phylloxera and its consequent impacts on host plants. With regard to soil moisture, the phylloxera population in our trial did not develop in 3 and 36\% of drought-stressed and wellwatered plants, respectively. It is worth noting that wellwatered pots had a water content of about $0.3 \mathrm{gg}^{-1}$, hence far lower than the soil saturated water content $\left(0.51 \mathrm{~g} \mathrm{~g}^{-1}\right)$, indicating that the roots were not subjected to waterlogging which might reduce the insect proliferation [37]. The root system of drought-stressed vines was significantly more infested showing numerous nodosities compared to W ones (Fig. 1). We want to point out that the maximum substrate temperatures were by about $3{ }^{\circ} \mathrm{C}$ higher (differences not statistically significant) in $\mathrm{D}$ pots compared to $\mathrm{W}$ ones (data not shown). Our data, hence, suggests that the water scarcity may exacerbate

Table 2 Shoot length, Leaf mass per area (LMA), dry biomass of leaf (DM leaves), stem (DM stem $_{\text {) }}$ and roots (DM root $)$ measured for $5 C$ and Riesling $\times 5 C(R R)$ plants 8 weeks after the beginning of treatments $(n=7-10)$. W = well-watered plants; $D=$ drought-stressed; $\mathrm{C}=$ control, non-phylloxerated; $\mathrm{P}=$ root phylloxerated. ${ }^{*}$ indicates statistically significant differences within the factors (Irrigation or Infestation). A significant interaction between factors (Irr x Inf) was observed in Shoot length (within C level: W $>$ D; within P level: W $>$ D) and $\mathrm{DM}_{\text {roots }}$ (within D level: C > P) measured in RR

\begin{tabular}{|c|c|c|c|c|c|c|c|c|c|c|}
\hline \multirow{3}{*}{ Traits } & \multicolumn{5}{|l|}{$5 C$} & \multicolumn{5}{|l|}{$\mathrm{RR}$} \\
\hline & \multicolumn{2}{|l|}{ Irrigation } & \multicolumn{2}{|l|}{ Infestation } & \multirow{2}{*}{$\frac{\text { Interaction }}{\operatorname{lrr} \times \operatorname{lnf}}$} & \multicolumn{2}{|l|}{ Irrigation } & \multicolumn{2}{|l|}{ Infestation } & \multirow{2}{*}{$\frac{\text { Interaction }}{\operatorname{lrr} \times \operatorname{lnf}}$} \\
\hline & W & $\mathrm{D}$ & $C$ & $P$ & & W & $\mathrm{D}$ & $C$ & $P$ & \\
\hline Shoot length, $\mathrm{m}$ & $5.3 \pm 0.2$ & $2.0 \pm 0.2^{*}$ & $3.8 \pm 0.2$ & $3.5 \pm 0.2$ & n.s. & $3.5 \pm 0.1$ & $1.4 \pm 0.1 *$ & $2.4 \pm 0.1$ & $2.5 \pm 0.1$ & $*$ \\
\hline LMA, $\mathrm{g} \mathrm{cm}^{-2}$ & $5.7 \pm 0.1$ & $5.6 \pm 0.1$ & $5.6 \pm 0.1$ & $5.7 \pm 0.1$ & n.s. & $5.8 \pm 0.1$ & $5.9 \pm 0.2$ & $6.1 \pm 0.1$ & $5.6 \pm 0.2^{*}$ & n.s. \\
\hline DM $M_{\text {leaves }} \mathrm{g}$ & $31.0 \pm 1.6$ & $13.9 \pm 1.5^{*}$ & $23.0 \pm 1.7$ & $21.9 \pm 1.4$ & n.s. & $23.7 \pm 0.9$ & $11.4 \pm 0.9^{*}$ & $17.6 \pm 1.0$ & $17.4 \pm 0.9$ & n.s. \\
\hline $\mathrm{DM}_{\text {stem }} \mathrm{g}$ & $26.8 \pm 1.3$ & $9.1 \pm 1.2^{*}$ & $18.7 \pm 1.3$ & $17.2 \pm 1.2$ & n.s. & $22.5 \pm 1.0$ & $9.0 \pm 0.9^{*}$ & $15.7 \pm 1.0$ & $15.8 \pm 0.9$ & n.s. \\
\hline $\mathrm{DM}_{\text {roots }} \mathrm{g}$ & $21.2 \pm 1.3$ & $23.8 \pm 1.2$ & $22.0 \pm 1.3$ & $23.1 \pm 1.2$ & n.s. & $22.2 \pm 1.0$ & $21.9 \pm 1.0$ & $22.6 \pm 1.0$ & $21.5 \pm 1.0$ & $*$ \\
\hline
\end{tabular}


Table 3 Glucose, fructose, sucrose, and starch concentrations measured in leaves (a), stems (b) and roots (c) of 5C and Riesling $\times 5 C$ (RR) 8 weeks after the beginning of treatments $(n=5-8)$. W = well-watered plants; $D=$ drought-stressed; $C=$ control, nonphylloxerated; $\mathrm{P}=$ root phylloxerated. * indicates statistically significant differences within the factors (Irrigation or Infestation). At root level, a significant interaction between factors (Irr x Inf) was observed in sucrose measured in 5C (within D level: C > P; within C level: W $<D$ ) and glucose (within W level: $C>P$; within C level: $W>D$ ) measured in RR

\begin{tabular}{|c|c|c|c|c|c|c|c|c|c|c|}
\hline \multirow[b]{3}{*}{ (a) Leaves } & \multicolumn{5}{|l|}{$5 C$} & \multicolumn{5}{|l|}{$\mathrm{RR}$} \\
\hline & \multicolumn{2}{|l|}{ Irrigation } & \multicolumn{2}{|l|}{ Infestation } & \multirow{2}{*}{$\begin{array}{l}\text { Interaction } \\
\operatorname{lr} \times \operatorname{lnf}\end{array}$} & \multicolumn{2}{|l|}{ Irrigation } & \multicolumn{2}{|l|}{ Infestation } & \multirow{2}{*}{$\begin{array}{l}\text { Interaction } \\
\operatorname{Irr} \times \operatorname{lnf}\end{array}$} \\
\hline & W & $D$ & C & $P$ & & W & $\mathrm{D}$ & C & $P$ & \\
\hline Glucose, $\mathrm{mg} \mathrm{g}^{-1}$ & $24.2 \pm 2.7$ & $15.1 \pm 2.8^{*}$ & $17.7 \pm 2.8$ & $21.7 \pm 2.7$ & n.s. & $14.7 \pm 1.1$ & $9.2 \pm 1.1^{*}$ & $12.3 \pm 1.1$ & $11.6 \pm 1.1$ & n.s. \\
\hline Fructose, $\mathrm{mg} \mathrm{g}^{-1}$ & $31.6 \pm 3.8$ & $18.7 \pm 3.8^{*}$ & $21.5 \pm 3.9$ & $28.8 \pm 3.7$ & n.s. & $13.7 \pm 1.1$ & $8.6 \pm 1.2^{*}$ & $11.3 \pm 1.1$ & $11.0 \pm 1.2$ & n.s. \\
\hline Sucrose, $\mathrm{mg} \mathrm{g}^{-1}$ & $101.5 \pm 12.7$ & $99.5 \pm 11.9$ & $89.7 \pm 13.0$ & $111.4 \pm 11.5$ & n.s. & $111.2 \pm 9.6$ & $110.4 \pm 10.0$ & $115.1 \pm 10.0$ & $106.4 \pm 9.6$ & n.s. \\
\hline Starch, mg g ${ }^{-1}$ & $2.5 \pm 0.4$ & $3.4 \pm 0.4$ & $3.1 \pm 0.4$ & $2.7 \pm 0.4$ & n.s. & $9.1 \pm 1.0$ & $3.9 \pm 1.1 *$ & $8.2 \pm 1.0$ & $4.8 \pm 1.1^{*}$ & n.s. \\
\hline (b) Stems & W & $\mathrm{D}$ & C & $P$ & $\operatorname{Irr} \times \operatorname{lnf}$ & W & $\mathrm{D}$ & C & $P$ & $\operatorname{Irr} \times \operatorname{Inf}$ \\
\hline Glucose, $\mathrm{mg} \mathrm{g}^{-1}$ & $7.6 \pm 0.6$ & $4.1 \pm 0.6^{*}$ & $5.7 \pm 0.6$ & $6.1 \pm 0.6$ & n.s. & $3.3 \pm 0.4$ & $4.9 \pm 0.4^{*}$ & $4.4 \pm 0.4$ & $3.8 \pm 0.4$ & n.s. \\
\hline Fructose, $\mathrm{mg} \mathrm{g}^{-1}$ & $4.7 \pm 0.3$ & $2.5 \pm 0.3^{*}$ & $3.7 \pm 0.3$ & $3.5 \pm 0.3$ & n.s. & $1.7 \pm 0.1$ & $2.1 \pm 0.1^{*}$ & $1.9 \pm 0.1$ & $1.9 \pm 0.1$ & n.s. \\
\hline Sucrose, $\mathrm{mg} \mathrm{g}^{-1}$ & $95.7 \pm 4.6$ & $93.4 \pm 4.6$ & $96.0 \pm 4.8$ & $93.1 \pm 4.5$ & n.s. & $80.4 \pm 4.5$ & $87.2 \pm 4.5$ & $84.0 \pm 4.5$ & $83.6 \pm 4.5$ & n.s. \\
\hline Starch, $\mathrm{mg} \mathrm{g}^{-1}$ & $11.5 \pm 1.7$ & $15.9 \pm 1.8$ & $15.1 \pm 1.8$ & $12.3 \pm 1.7$ & n.s. & $8.4 \pm 1.4$ & $19.1 \pm 1.4^{*}$ & $13.8 \pm 1.4$ & $13.7 \pm 1.4$ & n.s. \\
\hline (c) Roots & W & D & C & $P$ & $\operatorname{Irr} \times \operatorname{lnf}$ & W & $D$ & C & $P$ & $\operatorname{Irr} \times \operatorname{lnf}$ \\
\hline Glucose, $\mathrm{mg} \mathrm{g}^{-1}$ & $74.3 \pm 8.3$ & $60.1 \pm 8.0$ & $101.2 \pm 8.0$ & $33.1 \pm 8.3^{*}$ & n.s. & $72.8 \pm 7.4$ & $38.0 \pm 8.1^{*}$ & $84.1 \pm 8.1$ & $26.8 \pm 7.4^{*}$ & * \\
\hline Fructose, $\mathrm{mg} \mathrm{g}^{-1}$ & $17.5 \pm 2.0$ & $19.5 \pm 1.9$ & $27.6 \pm 1.9$ & $9.4 \pm 2.0^{*}$ & n.s. & $13.4 \pm 1.8$ & $13.7 \pm 1.9$ & $19.2 \pm 1.9$ & $7.9 \pm 1.8^{*}$ & n.s. \\
\hline Sucrose, $\mathrm{mg} \mathrm{g}^{-1}$ & $77.7 \pm 6.2$ & $95.3 \pm 6.0^{*}$ & $94.5 \pm 6.0$ & $78.5 \pm 6.2$ & * & $72.7 \pm 5.0$ & $93.7 \pm 5.0^{*}$ & $98.7 \pm 5.2$ & $67.6 \pm 4.8^{*}$ & n.s. \\
\hline Starch, $\mathrm{mg} \mathrm{g}^{-1}$ & $18.7 \pm 2.9$ & $17.1 \pm 3.0$ & $15.3 \pm 2.9$ & $20.4 \pm 3.0$ & n.s. & $21.7 \pm 2.7$ & $13.2 \pm 2.9^{*}$ & $18.3 \pm 2.9$ & $16.6 \pm 2.7$ & n.s. \\
\hline
\end{tabular}

the biotic stress, by increasing the insect's feeding damage/number of nodosities on plant roots. Interestingly, this result is not in accordance with the only other study found in the literature addressing the effects of watering on phylloxeration of vines [2] in which a greater gall density was reported for irrigated compared to nonirrigated plants in the pots. The contrasting plant-insect response to water scarcity observed in the two studies might be driven by several factors differing in the two experimental set-ups, i.e. microclimate, substrate characteristics (porosity, oxygen diffusion), competing soil fauna and flora, root architecture, drought/phylloxera tolerance of the used rootstocks and insect biotypes etc. $[3,12,15]$.

As expected, the drought stress had a significant negative impact on most of the measured functional traits. Both genotypes displayed a prompt stomatal closure, but Riesling scion buffered more efficiently the drop in the water potential (isohydric water strategy, [31]), showing at the same time a lower photosynthetic efficiency compared to 5C (Table 1). At first sight, phylloxeration did not cause shifts in the leaf functionality throughout the study period. However, a general trend toward lower transpiration rates and stomatal conductance values in the $\mathrm{P}$ group compared to $\mathrm{C}$ ones could be noticed in both genotypes, and especially in well-watered plants. The differences were found to be statistically significant on two out of six dates of measurements (Fig. 2 and
Additional file 1: Fig. S2) indicating that root infestation may impact, even if on a small extend, the water status and gas exchange of the aboveground organs. Under drought conditions, all vines were water-stressed and the effect of the pest could be detected earliest three weeks after inoculation and only in RR plants. As a likely consequence of high data variability and the lower sensibility of net photosynthesis to stress factors [21, 28], differences in A between the infestation levels were not evident. On the other hand, a significant drop of the maximum quantum yield of PSII after dark adaptation could be observed in well-watered Riesling plants at the peak of the treatments $(\mathrm{Fv} / \mathrm{Fm}$ of 0.81 vs 0.74 measured in $\mathrm{C}$ and $\mathrm{P}$, respectively), suggesting the occurrence of insect-induced perturbations in the photosynthetic apparatus $[13,42]$.

The leaf mass per area ratio (LMA) is often used to study the biomass allocation and productivity gradients within the aboveground organs under different stressors, since it scales positively with the carbon investments in secondary compounds such as tannins and lignins (Pérez-Harguindeguy et al., 2016 [35, 42];). Phylloxera infestation apparently increased the stress experienced at the leaf-level leading to a reduction of LMA in the Riesling scion. This would suggest that, despite similar photosynthetic rates, phylloxerated RR undergoes less carbon investment per unit leaf area construction compared to control. Similarly to LMA, the biotic attack 
coupled to drought stress significantly reduced the root biomass of RR and limited the shoot length by about $20 \%$ (1.2 vs $1.5 \mathrm{~m}$ as measured in DP and DC plants, respectively). Hence, compensatory growth in response to root herbivory suggested by other authors [10, 23] was not highlighted in our study at the aboveground, neither at the belowground level. The lower primary metabolites allocation in biomass observed in Riesling might be a direct consequence of i) the carbon export toward the phylloxera population which has been suggested that acts as a strong sink [24, 46], as well as ii) an effect of the redirection of energy in the secondary metabolic pathways (defense, repair, signaling, phytohormonal networks [11, 23];). In fact, it has been recently demonstrated that plants tend to accelerate carbon allocation for defense under stress synthetizing a large amounts of secondary metabolites, i.e. organic volatiles, flavonoids, stilbenes etc. $[1,11,27]$, a process that requires conspicuous energy investment [23, 47]. Apparently, 5C plants showed a higher tolerance to the biotic attack compared to the grafted Riesling, although a slight and not significant reduction of shoot length and aboveground biomass could be observed also in these plants.

To our knowledge, the present study addresses for the first time, the whole-plant NSC dynamics under phylloxera and drought stress. The values of NSC measured in leaves, stems, and roots are in overall agreement with data reported in the literature for grapevine [20,39, 44]. The drought treatment led to a general depletion of monosaccharides in both above and below-ground organs, with the exception of RR stems where glucose and fructose increased as a likely consequence of late summer sugars translocation toward perennial organs characterizing this less vigorous cultivar. However, the high sucrose concentration observed in all plants and organs indicates that phloem activity and translocation was still intense. The depletion of NSC due to drought stress has been already reported and linked to stomatal closure and reduced carbon fixation coupled to the increased energetic demand for respiration, basal metabolism, osmoregulation, and synthesis of defense compounds [19]. In our study, the water limitation caused a $40 \%$ starch reduction (main storage compound) in roots of grafted Riesling, but not in own-rooted 5C. On the basis of the above we can speculate that the more isohydric behavior of RR plants induced an imbalance between carbon uptake via photosynthesis and carbon substrate demand (respiration, turgor maintenance, defense, repair) leading to a massive loss of carbohydrates [19, 29] and consequent reduction of biomass.

Apparently, infestation did not influence NSC levels in the aboveground organs, with the exception of a marked reduction of starch found in the leaves of Riesling. Similarly to what observed in morphological traits, this result supports the idea that the insect actively limits carbon allocation and storage in the leaves, while likely stimulates its translocation toward galling habit or/and its usage in alternative metabolic pathways. Interestingly, differences in starch concentration were not observed in the stem tissue (about $13.8 \mathrm{mgg}^{-1}$ in both $\mathrm{C}$ and $\mathrm{P}$ groups). However, at the root level, significant reductions of all soluble sugars were recorded when comparing phylloxerated and control plants. These results might suggest that in phylloxerated plants the sugars are redirected elsewhere, as for example in the synthesis of defense compounds in response to herbivory. Furthermore, we can also speculate that the carbon reserves are, as least partially, withdrawn by the insect population $[10,18,46]$. The synergic effect of phylloxera and water stress was highlighted for sucrose and glucose measured in $5 \mathrm{C}$ and $\mathrm{RR}$ respectively; indicating that the infestation may interfere with water uptake exacerbating the water stress. The absence of statistically significant differences in starch between the infestation levels may be due to the harsh environmental conditions of the greenhouse (high temperatures and water pressure deficits) which limited carbon fixation and storage in all study plants, as well as a consequence of high data variability and relatively limited number of replicates $(n=5-8)$. Similarly, Ryan et al. [39] failed in pointing out clear differences in starch concentration between infested and uninfested roots, while other authors reported a general increase of it $[18,24]$. However, a closer look to our data reveals that the infested root-tips of $5 \mathrm{C}$ plants contained higher (but not significant) concentration of starch compared to $C$, especially when subjected to drought stress. This might indicate that Teleki $5 \mathrm{C}$ genotype better tolerates root infestation compared to RR by maintaining certain carbon storage in the roots.

To better address the effect of phylloxeration on the whole-plant carbon metabolism, we estimated the theoretical total amount of carbohydrates available in the experimental vines by multiplying the NSC with the dry mass of different organs. This rough calculation showed that control roots in both genotypes contained about $5 \mathrm{~g}$ of NSC, while in infested roots the value was limited to only $3 \mathrm{~g}$. Interestingly, at the aboveground level RR plants showed a depletion of total available NSC (-6\%), while $5 \mathrm{C}$ plants had similar values in $\mathrm{C}$ and $\mathrm{P}$ groups. However, when the whole plant organism (leaves, stems, roots) was considered, the carbon availability of the phylloxerated group was by $30 \%$ (RR) and $15 \%$ (5C) lower compared to control ones. These results confirmed, once again, that the pest influences the mobility of metabolites between above and below ground organs leading to a general reduction of carbon resources. Extending the research on secondary metabolites produced by plants under different stresses would shed light on 
the fraction of nutrients that is redirected to sustain plants defense mechanisms and that which is actually withdrawn by the insect population.

\section{Conclusion}

Our experiment represents the most complete report on the whole-vine response to root infestation of phylloxera. Through measurements of leaf physiology, we demonstrated that the insect is able to impact water and carbon metabolism of plants, likely enforcing the sink strength of the roots by stimulating the carbon translocation in favor of the galling habit and/or redirecting the sugars toward defense metabolic pathways. Moreover, we showed that phylloxera reprograms vine carbon allocation and development, while preventing or limiting biomass compensation. Furthermore, to our knowledge this is the first study addressing the combined effects of drought and phylloxera on vine physiology. A more intense root infestation was observed in drought-stressed plants compared to watered ones, suggesting that events of water shortage favor the insect's feeding damage. The synergic effects of biotic-abiotic stress on vine could be clearly detected in physiological traits, as well as in shoot length and root biomass. In particular, significant differences in LMA, roots' dry mass, and sugars concentration suggested that belowground infestation imposes a considerable stress to the plants, which might exacerbate the negative effects of drought. Teleki $5 \mathrm{C}$ is a tolerant rootstock supporting large population of phylloxera, but efficiently buffering negative effects on plant development. The overall more marked response of grafted Riesling compared to own-rooted $5 \mathrm{C}$, indicates a higher sensitivity to phylloxera of the former genotype, and demonstrates the potential ability of the scion in influencing the whole-plant physiology.

\section{Methods}

\section{Plant material and experimental set-up}

The study was carried out in the greenhouse of the Institute of Viticulture and Pomology, BOKU, Tulln (Lower Austria) in spring-summer 2018. As host plant material the rootstock Teleki $5 \mathrm{C}$ ( $V$. riparia $\mathrm{x}$ $V$. berlandieri) without or with grafted Riesling scion (5C and RR, respectively) were selected. Plants were provided by a nursery (Reben IBY KEG) where the formal identification of the plant material was undertaken. A voucher specimen of this material has not been deposited in a publicly available herbarium. At the beginning of April, 50 plants of $5 \mathrm{C}$ (one year old) and 50 of RR (two years old) were potted in seven liters pots containing a mixture of natural soil (chernozem) collected from a nearby site ([9] Digitale Bodenkarte Österreich; https://gis.bmnt.gv.at/ eBOD) and perlite (Premium Perlite, Gramoflor; 70:
30). The water content at field capacity of the mixture, defined as the amount of water content held in the soil after excess water has drained away, was $0.51 \pm 0.03 \mathrm{~g} \mathrm{~g}^{-1}$. The plants were fertilized (ENTEC vino, EuroChem Agro GmbH; $23 \mathrm{~g}$ per pot) and maintained in well-watered conditions by drip irrigation. After about eight weeks of growth, the experimental plants were trimmed to uniform the canopy size by leaving 15 leaves (total shoot length of about $75 \mathrm{~cm}$ ). One week after, half of the plants per genotype were root-inoculated with 100 phylloxera eggs (P) collected from a field population developing on leaves of adult $5 \mathrm{C}$ plants. The non-infested plants were considered as control $(C)$. All the pots were enclosed and accurately sealed in a bag made of polypropylene tissue (mesh $125 \mu \mathrm{m}$ ) preventing the spread of phylloxera.

The day after inoculation, the pots were randomly disposed equally spaced, on tables and subdivided into two additional groups per infestation category, i.e. wellwatered plants (W) and drought-stressed (D) plants. W vines were irrigated daily with about $150 \mathrm{ml}$ of water. The drought treatment consisted of the progressive reduction of irrigation volumes aimed at reducing the leaf stomatal conductance at values corresponding to about 30\% of those recorded in $\mathrm{W}$ plants (moderate water deficit). Soil water content was measured at the end of the treatment. About $8 \mathrm{~h}$ after the last irrigation, 5 plants per experimental category (W and D) were randomly selected, $5-8 \mathrm{~g}$ of soil was collected from the central part of the pots and the fresh weight measured. The samples were then placed in an oven $\left(48 \mathrm{~h}\right.$ at $\left.45^{\circ}\right)$ to get their dry weight. The soil water content was calculated as (fresh weight - dry weight) / dry weight, and expressed in $\mathrm{g} \mathrm{g}^{-1}$.

To summarize, the experimental set up consisted on a full $2 \times 2$ factorial design with Irrigation and Infestation as main factors and their combinations, for a total of four treatments per genotype, i.e. well-watered not infested (WC), wellwatered phylloxerated (WP), drought-stressed not infested (DC) and drought-stressed phylloxerated plants (DP). The treatments were maintained for eight weeks.

Air temperature and relative humidity were recorded on an hourly basis during the whole study period using three data-loggers (UT330B, Uni-trend Technology, Hong Kong) installed at $1.5 \mathrm{~m}$ and facing North. To evaluate the atmospheric evaporative demand, average midday water pressure deficit $(\mathrm{kPa})$ was calculated as the difference between the actual amount of moisture in the air and the maximum moisture that the air hold at saturation. Substrate temperatures were measured with mini data-loggers (Thermochron iButton, iButtonLink, LLC, Whitewater, WI) installed at a depth of about 20 $\mathrm{cm}$ of three experimental pots per watering category (six pots in total). 


\section{Physiological measurements and sampling}

In order to adjust the watering, maintain a moderate degree of drought stress in D plants, and assess eventual differences among experimental treatments, stomatal conductance to water vapor $\left(\mathrm{g}_{\mathrm{s}}\right)$, transpiration rates $\left(\mathrm{E}_{\mathrm{L}}\right)$, net photosynthesis (A), sub-stomatal $\mathrm{CO}_{2}$ (ci), leaf surface temperature $\left(\mathrm{T}_{\text {leaf }}\right)$, and photosynthetic efficiency $(\mathrm{Fv} / \mathrm{Fm})$ were measured weekly during the eight-week long treatment. Measurements were performed between 11 and $14 \mathrm{~h}$ on at least one mature fully expanded and undamaged leaf per plant. At least five randomly selected plants per genotype and experimental treatment were measured in each day, for a total of six dates. $g_{s}$, $\mathrm{E}_{\mathrm{L}}, \mathrm{T}_{\text {leaf }}$, and $\mathrm{A}$ were measured with the gas-exchange system LCpro-SD (ADC BioScientific Ltd., Hertfordshire, UK). The Fv/Fm was recorded on dark-adapted leaves as a quantitative measure of the maximum efficiency of PSII using a portable fluorimeter (Handy Pea, Hansatech, Norfolk, UK). The parameter has been widely used as a sensitive indicator of photosynthetic performance under stress conditions [13, 40].

During measurements, the air temperature and relative humidity in the greenhouse averaged about $32{ }^{\circ} \mathrm{C}$ and $40 \%$, respectively, while the photosynthetic photon flux density ranged between 600 and $1000 \mu \mathrm{mol} \mathrm{m}^{-2} \mathrm{~s}^{-1}$. For details on climatic parameters see Additional file 1: Figure S1.

Eight weeks after the beginning of treatments, at the peak of the abiotic and biotic stress, physiological measurements were performed on six to eight plants per experimental category. In addition, minimum $\left(\psi_{\min }\right)$ and stem water potentials $\left(\psi_{\text {stem }}\right)$ were assessed by means of a Scholander pressure chamber (3000 Series Plant Water Status Consoles, Soilmoisure, Santa Barbara, CA [41];) sampling the closest leaves to the one used for photosynthesis measurements. The leaf for $\psi_{\min }$ was collected, wrapped in cling film, inserted in a sealed plastic envelope, and stored in a cool bag. On the other hand, $\psi_{\text {stem }}$ was assessed in leaves that were bagged in cling film and covered with aluminum foil two hours before sampling. All leaves were measured within two hours after sampling.

Furthermore, right after noninvasive gas-exchange measurements, the leaves were sampled, snap frozen in liquid nitrogen and stored at $-80^{\circ} \mathrm{C}$ for subsequent non-structural carbohydrate (NSC) analyses (see below). A $5 \mathrm{~cm}$ long stem segment cut from the central part of the shoot and a root sample of about $2 \mathrm{~g}(15 \mathrm{~mm}$ long root tips) were also collected from each plant and stored as described above. The roots were previously abundantly rinsed with distilled water to remove soil particles and insects.

\section{Assessment of phylloxera infestation}

With the aim to highlight eventual differences in the root infestation of $\mathrm{P}$ vines among the experimental treatments, the plants were gently uprooted and the roots observed under a stereo microscope. Two integrated parameters were calculated [36]. In particular, the infestation frequency was defined as the ratio of inoculated plants showing infestation symptoms and the total number of actually inoculated vines. The infestation intensity was further classified into four assessment classes, i.e. $1=$ presence of a low number of root nodosities; $2=10$ to 100 young (white to lightyellow color) nodosities; $3=$ up to 200 young and old (dark brown) nodosities; $4>200$ nodosities, developed on older lignified roots, as well [36]. P plants that did not show signs of insect infestation were excluded from all the experimental measurements and sampling.

\section{Measurements of morphological traits}

In order to study the biomass allocation in the experimental vines, additional morphological measurements [34] were performed on the plant material $(n=7-10)$. The two leaves used for $\psi$ measurements (see above), were re-hydrated overnight by immersing their petiole in distilled water while wrapped in cling film. The petiole was then cut, the leaf blades scanned, and the area measured with imageJ (https:// imagej.nih.gov/ij). The mass of each leaf was recorded after drying $\left(48 \mathrm{~h}\right.$ at $70^{\circ} \mathrm{C}$ ) and the LMA (leaf mass per area) calculated as dry mass / leaf area (PérezHarguindeguy et al., 2016).

The stem of all plants was cut at the root collar. The root systems were gently washed with tap water in order to remove residual soil particles and oven-dried $(72 \mathrm{~h}$ at $\left.70{ }^{\circ} \mathrm{C}\right)$ to get the dry biomass $\left(\mathrm{DM}_{\text {roots }}\right)$. The absolute shoot length was measured with a meter tape, the leaves were detached and the dry mass of the two organs $\left(\mathrm{DM}_{\text {stems }}\right.$ and $\left.\mathrm{DM}_{\text {leaves }}\right)$ was recorded after drying.

\section{Non-structural carbohydrates (NSC) analyses}

To verify whether the stressors influence carbon allocation/translocation dynamics in different experimental categories, NSC (major source of energy for plants, [47]) were measured at the end of the treatments. After being ground to fine powder in liquid nitrogen and freeze-dried for $48 \mathrm{~h}$, about $50 \mathrm{mg}$ of the leaf, root, and stem samples were used to measure the NSC concentration according to Landhäusser et al. [26]. Total soluble sugars were extracted in $80 \%$ ethanol (three boiling cycles) and the supernatant filtered at $0.45 \mu \mathrm{m}$ nylon syringe filter. The collected supernatant from the three extractions was pooled together. After necessary dilution, the samples were analyzed with anion exchange chromatography (Dionex ${ }^{\mathrm{m}}$ ICS-5000, Thermo Fischer Scientific, Waltham, MA) using a Dionex CarboPac ${ }^{\mathrm{Tm}}$ PA20 column $(3 \times 150 \mathrm{~mm})$ coupled with 
a Dionex CarboPac ${ }^{\mathrm{Tm}}$ PA20 guard column $(3 \times 30 \mathrm{~mm})$ kept at $30^{\circ} \mathrm{C}$ and using $\mathrm{NaOH} 52 \mathrm{mM}$ as eluent under isocratic conditions (flow rate $0.5 \mathrm{ml} / \mathrm{min}$ ). Glucose, fructose and sucrose were quantified using their reference standards with the software Chromeleon ( $v$ 7.2, Thermo Scientific, Waltham, MA). The starch contained in the pellet was converted to glucose with $\alpha$-amilase (70 units per sample, $1 \mathrm{ml}$ ) followed by amyloglucosidase ( 6 units per $0.1 \mathrm{ml}$ of subsample; for details see [26]). After digestion of the pellet, the samples were treated with chloroform $(1: 1 \mathrm{v} / \mathrm{v})$, the aqueous layer was filtered, and the glucose hydrolysate measured as described above.

\section{Data analyses}

Statistical analysis was performed in R (v 3.5.1) and SigmaPlot (v 13, Systat Software Inc., San Jose, CA). The effect of different treatments was tested separately for each parameter and for each genotype independently. Normality of data distribution was tested using the 'qqPlot' function ('CAR' package). A General Liner Model was run to detect differences among values of traits measured in the four experimental categories per genotype. Each trait was considered as a response variable, while Infestation and Irrigation were treated as explanatory variables (factors). To detect statistically significant differences among groups a multiple comparison procedure based on the Holm-Sidak method was run on the data. The categorical root-infestation data recorded for P plants was analyzed using chi-square test. All results were considered statistically significant at $P \leq 0.05$. Mean \pm standard errors of the mean are reported.

\section{Supplementary information}

The online version of this article (https://doi.org/10.1186/s12870-019-2017-2) contains supplementary material, which is available to authorized users.

\section{Additional file 1: FigureS1. Microclimatic data recorded in the} greenhouse during the experimental period: average midday water pressure deficit (grey area, right axis), minimum (closed circles) and maximum (open circles) daily temperatures (left axis). The two arrows indicate the inoculation and the final sampling days, respectively. Figure S2. Stomatal conductance to water vapor $\left(g_{s}\right)$ measured in $5 C(a)$ and Riesling grafted on $5 C(b)$ during treatments application $(n=4-7)$. $\mathrm{W}=$ well-watered plants; $\mathrm{D}=$ droughtstressed; $C=$ control, non-phylloxerated; $P=$ root phylloxerated. Letters and asterisk indicate statistically significant difference within Irrigation (Factor I; W and D) and Infestation (Factor II; C and P), respectively. No statistically significant interaction between factors was observed. Figure $\mathbf{S 3}$. Leaf temperature $\left(T_{\text {leaf }}\right)$ measured in 5C (a) and Riesling grafted on 5C (b) during treatments application $(n=4-7)$. $W=$ well-watered plants; $D=$ drought-stressed; $C=$ control, nonphylloxerated; $\mathrm{P}=$ root phylloxerated. Letters denote statistically significant differences within Irrigation (Factor I; W and D). No statistically significant differences within factor Infestation or interaction between factors were observed Figure S4. Sub-stomatal $\mathrm{CO}_{2}$ (Ci) measured in $5 \mathrm{C}$ (a) and Riesling grafted on 5C (b) during treatments application $(n=4-7)$. $W=$ well-watered plants; $D=$ drought-stressed; $C=$ control, non-phylloxerated; $P=$ root phylloxerated. Letters denote statistically significant differences within Irrigation (Factor I; W and D). No statistically significant differences within factor Infestation or interaction between factors were observed.

\author{
Abbreviations \\ A: net photosynthesis; ci: sub-stomatal $\mathrm{CO}_{2}$; DM: dry biomass; \\ $E_{L}$ : transpiration rates; Fv/Fm: photosynthetic efficiency; $g_{s}$ : stomatal \\ conductance to water vapor; LMA: leaf mass per area; NSC: non-structural \\ carbohydrates; $T_{\text {leaf: }}$ leaf surface temperature; $\psi_{\text {min }}$ : minimum water potential; \\ $\psi_{\text {stem: }}$ stem water potential
}

\section{Acknowledgements}

The authors are grateful to Federica De Berardinis, Verena Dockner, Gregor Wiedeschitz, and Miroslaw Wierzyk for technical assistance.

\section{Authors' contributions}

T.S. and A.F. conceived and designed the experiment. T.S. and A.G.G. conducted the experiment. A.F. supervised the experiment. T.S. and J.C.H. performed NSC analyses T.S. conducted statistical analyses and wrote the manuscript. All authors critically revised, commented and contributed to the final version of the manuscript. All authors read and approved the final manuscript.

\section{Funding}

Not applicable.

\section{Availability of data and materials}

The datasets used and analyzed during the current study are available from the corresponding author on reasonable request.

\section{Ethics approval and consent to participate}

The use of plants and animals (insects) in the present study comply with international, national and/or institutional guidelines.

\section{Consent for publication}

Not applicable.

\section{Competing interests}

The authors declare that they have no competing interests. See lines $493-$ 494.

Received: 7 May 2019 Accepted: 5 September 2019

Published online: 18 September 2019

\section{References}

1. Atkinson NJ, Urwin PE. The interaction of plant biotic and abiotic stresses: from genes to the field. J Exp Bot. 2012;63:3523-44.

2. Bates RT, English-Loeb G, Dunst RM, Taft T, Lakso A. The interaction of phylloxera infection, rootstock and irrigation on young Concord grapevine growth. Vitis. 2001;40:225-8.

3. Bauerle TL, Eissenstat DM, Granett J, Gardner DM, Smart DR. Consequences of insect herbivory on grape fine root systems with different growth rates. Plant Cell Environ. 2007:30:786-95.

4. Benheim D, Rochfort S, Robertson E, Potter ID, Powell KS. Grape phylloxera (Daktulosphaira vitifoliae) - a review of potential detection and alternative management options. Ann Appl Biol. 2012;161:91-115.

5. Blanchfield AL, Robinson SA, Renzullo LJ, Powell KS. Phylloxera-infested grapevines have reduced chlorophyll and increased photoprotective pigment content: can leaf pigment composition aid pest detection? Funct Plant Biol. 2006;33:507-14.

6. Castex V, Beniston M, Calanca P, Fleury D, Moreaud J. Pest management under climate change: the importance of understanding tritrophic relations. Sci Total Environ. 2018;616-617:397-407.

7. Chitkowski RL, Fisher JR. Effect of soil type on the establishment of grape phylloxera colonies in the Pacific northwest. Am J Enol Viticult. 2005;56:207-11.

8. Degu A, Hochberg U, Wong DCJ, Alberti G, Lazarovitch N, Peterlunger E, Castellarin SD, Herrera JC, Fait A. Swift metabolite changes and leaf shedding are milestones in the acclimation process of grapevine under prolonged water stress. BMC Plant Biol. 2019;19:69.

9. Digitale Bodenkarte Österreich - eBOD. https://uww.naturland-noe.at/digitalebodenkarte-oesterreich-ebod. Accessed 15 April 2019.

10. Eitle MW, Cargnoni M, Acar A, Crespo Martinez S, Failla O, Kaul HP, Griesser M, Forneck A. Phylloxeration effects on the sink activity and assimilation rate in 
phylloxera (Daktulosphaira vitifoliae Fitch) infested grapevines (Vitis spp.). Acta Hortic. 2017; 1188: 291-298.

11. Eitle MW, Loacker J, Meng-Reiterer J, Schuhmacher R, Griesser M, Forneck A. Polyphenolic profiling of roots (Vitis spp.) under grape phylloxera (D. vitifoliae Fitch) attack. Plant Physiol Biochem. 2019;135:174-81.

12. Erb M, Lu J. Soil abiotic factors influence interactions between belowground herbivores and plant roots. J Exp Bot. 2013;64:1295-303.

13. Feng W, Qi S, Heng Y, Zhou Y, Wu Y, Liu W, He L, Li X. Canopy vegetation indices from in situ hyperspectral data to assess plant water status of winter wheat under powdery mildew stress. Front Plant Sci. 2017;8:1219.

14. Forneck A, Kleinmann S, Blaich R, Anvari SF. Histochemistry and anatomy of phylloxera (Daktulosphaira vitifoliae) nodosities on young roots of grapevine (Vitis spp). Vitis. 2002:41:93-7.

15. Forneck A, Powell KS, Walker MA. A scientific opinion: improving the definition of grape phylloxera biotypes and standardizing biotype screening protocols. Am J Enol Viticult. 2016;67:371-6.

16. Galetto L, Miliordos DE, Pegoraro M, Sacco D, Veratti F, Marzachì C, Bosco D. Acquisition of Flavescence dorée phytoplasma by Scaphoideus titanus ball from different grapevine varieties. Int J Mol Sci. 2016;17:1563.

17. Granett J, Walker MA, Kocsis L, Omer AD. Biology and management of grape phylloxera. Annu Rev Entomol. 2001;46:387-412.

18. Griesser M, Lawo NC, Crespo-Martinez S, et al. Phylloxera (Daktulosphaira vitifoliae Fitch) alters the carbohydrate metabolism in root galls to allowing the compatible interaction with grapevine (Vitis ssp.) roots. Plant Sci. 2015;234:38-49.

19. Hartmann $\mathrm{H}$, Trumbore $\mathrm{S}$. Understanding the roles of non-structural carbohydrates in forest trees - from what we can measure to what we want to know. New Phytol. 2016;211:386-403.

20. Herrera JC, Bucchetti B, Sabbatini P, Comuzzo P, Zulini L, Vecchione A, Peterlunger E, Castellarin SD. Effect of water deficit and severe shoot trimming on the composition of Vitis vinifera L. merlot grapes and wines. Aust J Grape Wine R. 2015;21:254-65.

21. Herrera JC, Hochberg U, Degu A, Sabbatini P, Lazarovitch N, Castellarin SD, Fait A, Alberti $G$, Peterlunger $\mathrm{E}$. Grape metabolic response to postveraison water deficit is affected by interseason weather variability. J Agric Food Chem. 2017;65:5868-78.

22. Holbrook NM, Zwieniecki M. Vascular transport in plants. 1st ed. London, UK: Elsevir Academic Press; 2005.

23. Johnson SN, Erb M, Hartley SE. Roots under attack: contrasting plant responses to below- and aboveground insect herbivory. New Phytol. 2016;210:413-8.

24. Kellow AV, Sedgley M, Van Heeswijck R. Interaction between Vitis vinifera and grape phylloxera: changes in root tissue during nodosity formation. Ann Bot. 2004;93:58190.

25. Knipfer T, Eustis A, Brodersen C, Walker AM, McElrone AJ. Grapevine species from varied native habitats exhibit differences in embolism formation/repair associated with leaf gas exchange and root pressure. Plant Cell Environ. 2015;38:1503-13.

26. Landhäusser SM, Chow PS, Dickman LT, et al. Standardized protocols and procedures can precisely and accurately quantify non-structural carbohydrates. Tree Physiol. 2018;38:1764-78.

27. Lawo NC, Weingart GJF, Schuhmacher R, Forneck A. The volatile metabolome of grapevine roots: first insights into the metabolic response upon phylloxera attack. Plant Physiol Biochem. 2011;49:1059-63.

28. Lovisolo C, Perrone I, Carra A, Ferrandino A, Flexas J, Mediano H, Schubert A. Drought-induced changes in development and function of grapevine (Vitis spp.) organs and in their hydraulic and nonhydraulic interactions at the whole-plant level: a physiological and molecular update. Funct Plant Biol. 2010; 37: 98-116.

29. McDowell NG, Beerling DJ, Breshears DD, Fisher RA, Raffa KF, Stitt M The interdependence of mechanisms underlying climate-driven vegetation mortality. Trends Ecol Evol. 2011;26:523-32.

30. Nabity PD, Haus MJ, Berenbaum MR, DeLucia EH. Leaf-galling phylloxera on grapes reprograms host metabolism and morphology. Proc Natl Acad Sci U S A. 2013;110:16663-8.

31. Nardini A, Savi T, Trifilò P, Lo Gullo MA. Drought stress and the recovery of xylem embolism. In: Canovas FM, Lüttge U, Matyssek R, editors. Progress in botany. Berlin Heidelberg: Springer; 2017. p. 197-231.

32. Omer AD, Granett J. Relationship between grape phylloxera and fungal infections in grapevine roots. J Plant Dis Protect. 2000;107:285-94.

33. Peressotti E, Wiedemann-Merdinoglu S, Delmotte F, Bellin D, Di Gaspero G Testolin R, Merdinoglu D, Mestre P. Breakdown of resistance to grapevine downy mildew upon limited deployment of a resistant variety. BMC Plant Biol. 2010;10:147.
34. Pérez-Harguindeguy N, Díaz S, Garnier E, et al. New handbook for standardised measurement of plant functional traits worldwide. Aust J Bot. 2013;61:167-234.

35. Petruzzellis F, Nardini A, Savi T, Tonet V, Castello M, Bacaro G. Less safety for more efficiency: water relations and hydraulics of the invasive tree Ailanthus altissima (Mill.) Swingle compared to native Fraxinus ornus L. Tree Physiol. 2019; 39: 76-87.

36. Porten M, Huber L. An assessment method for the quantification of Daktulosphaira vitifoliae (Fitch) (hem., Phylloxeridae) populations in the field. J Appl Entomol. 2003;127:157-62.

37. Powell KS, Cooper PD, Forneck A. The biology, physiology and host-plant interactions of grape phylloxera Daktulosphaira vitifoliae. Adv Insect Physiol. 2013:45:59-218

38. Rouault G, Candau JN, Lieutier F, Nageleisen LM, Martin JC, Warzée N. Effects of drought and heat on forest insect populations in relation to the 2003 drought in Western Europe. Ann Forest Sci. 2006;63:613-24.

39. Ryan FJ, Omer AD, Aung LH, Granett J. Effects of infestation by grape phylloxera on sugars, free amino acids, and starch of grapevine roots. Vitis. 2000:39:175-6.

40. Savi T, Bertuzzi S, Branca S, Tretiach M, Nardini A. Drought-induced xylem cavitation and hydraulic deterioration: risk factors for urban trees under climate change? New Phytol. 2015;205:1106-16.

41. Savi T, Casolo V, Luglio J, Bertuzzi S, Trifilò P, Lo Gullo MA, Nardini A. Species-specific reversal of stem xylem embolism after a prolonged drought correlates to endpoint concentration of soluble sugars. Plant Physiol Biochem. 2016a;106:198-207.

42. Savi T, Marin M, Luglio J, Petruzzellis F, Mayr S, Nardini A. Leaf hydraulic vulnerability protects stem functionality under drought stress in Salvia officinalis. Funct Plant Biol. 2016b;43:370-9.

43. Savi T, Miotto A, Petruzzellis F, Losso A, Pacilè $S$, Tromba G, Mayr S, Nardini A. Drought-induced embolism in stems of sunflower: a comparison of in vivo micro-CT observations and destructive hydraulic measurements. Plant Physiol Biochem. 2017;127:24-9.

44. Tombesi S, Cincera I, Frioni T, Ughini V, Gatti M, Palliotti A, Poni S. Relationship among night temperature, carbohydrate translocation and inhibition of grapevine leaf photosynthesis. Environ Exp Bot. 2019;157:293-8.

45. Webb LB, Whetton PH, Barlow EWR. Modelled impact of future climate change on the phenology of winegrapes in Australia. Aust J Grape Wine R. 2007;13:165-75.

46. Wieczorek K, Hensler S, Forneck A. Displaying sink-source flux in phylloxerated grapevines by microscopic techniques. Acta Hortic. 2014;1045: 29-32.

47. Zhou S, Lou YR, Tzin V, Jander G. Alteration of plant primary metabolism in response to insect herbivory. Plant Physiol. 2015;169:1488-98.

\section{Publisher's Note}

Springer Nature remains neutral with regard to jurisdictional claims in published maps and institutional affiliations.
Ready to submit your research? Choose BMC and benefit from:

- fast, convenient online submission

- thorough peer review by experienced researchers in your field

- rapid publication on acceptance

- support for research data, including large and complex data types

- gold Open Access which fosters wider collaboration and increased citations

- maximum visibility for your research: over $100 \mathrm{M}$ website views per year

At $\mathrm{BMC}$, research is always in progress.

Learn more biomedcentral.com/submissions 